\title{
Nanostructured Hydroxyapatite from Hen's Eggshells Using Sucrose as a Template
}

\author{
Marla Karolyne dos Santos Horta * (1), Francisco José Moura ${ }^{a}$, \\ Marilza Sampaio Aguilarb, Cecília Buzatto Westinc, José Brant de Campos ${ }^{d}$ (1), \\ Suzana Bottega Peripollid (1), Vitor Santos Ramos ${ }^{d}$, Maria Isabel Navarro ${ }^{e}$, Bráulio Soares Archanjo ${ }^{e}$ \\ ${ }^{a}$ Pontifícia Universidade Católica do Rio de Janeiro, Departamento de Engenharia Química e de \\ Materiais, Marquês de São Vicente, 225, Gávea, CEP 22451-900, Rio de Janeiro, RJ, Brasil. \\ ${ }^{b}$ Universidade Estácio de Sá, Departamento de Química, Rio de Janeiro, RJ, Brasil. \\ 'Universidade Estadual de Campinas, Departamento de Engenharia Quimica, Campinas, SP, Brasil. \\ ${ }^{d}$ Universidade do Estado do Rio de Janeiro, Departamento de Engenharia Mecânica, Rio de Janeiro, RJ, Brasil. \\ eInstituto Nacional de Metrologia, Qualidade e Tecnologia, Divisão de Metrologia de Materiais, \\ Rio de Janeiro, RJ, Brasil.
}

Received: June 20, 2020; Revised: September 18, 2020; Accepted: October 07, 2020

\begin{abstract}
The nanostructured hydroxyapatite (HAp) was synthesized by precipitation from aqueous phase, using hen's eggshells and different sucrose concentrations. The XRD results confirmed the formation of HAp, with crystallite size of about 15-22 nm. The SEM and TEM characterization showed morphological changes when increasing the amount of sucrose used, with the tendency to form spheroidal particles. The specific surface area increases from 36 to $93 \mathrm{~m}^{2} \cdot \mathrm{g}^{-1}$ as the amount of sucrose used increases. Our results indicated that sucrose can be used as a promising additive/template, easy to obtain at low cost. In addition to contributing to the recycling of this biowaste (eggshells), the synthesized HAp has the potential to be used in bone tissue engineering applications, since the samples were no cytotoxicity to dental pulp stem cells in the in vitro assessment by resazurin assay.
\end{abstract}

Keywords: Hydroxyapatite, eggshell, sucrose, biowaste, biomaterial.

\section{Introduction}

The interest in hydroxyapatite (HAp) as a biomaterial is because it is the main mineral phase of teeth and bones, representing 30 to $70 \%$ by mass of hard tissue. These data demonstrate its high degree of biocompatibility and similarities with some bone properties, including bioactivity, biodegradability and osteoconductivity ${ }^{1}$.

Studies report that nanostructured hydroxyapatite provides better biofunctionality, bioactivity ${ }^{2}$ and also exhibits greater resorption capacity ${ }^{3,4}$. Nanohydroxyapatite (n-Hap) has a larger surface area resulting in better cell adhesion and cell-matrix interactions ${ }^{5,6}$.

Hydroxyapatite can be extracted from bovine and pigs bones, fish scales ${ }^{7-12}$ and can also be synthesized from natural calcium sources such as hen's eggshells, shells, corals ${ }^{13-15}$ through chemical reactions. Hen's eggs are among the most consumed foods in the world and, therefore, a large amount of waste is generated. This makes the hen's eggshells a cheap and abundant raw material, reducing costs and bringing environmental benefits with their recovery ${ }^{16}$.

Physical-chemical properties, such as the particle size, porosity, morphology and surface properties must be considered in the synthesis of the compounds. Thus, for better particle growth control, new approaches have been studied, such as use additives in the precipitation methods.

*e-mail: marla.horta@hotmail.com
These additives, also called templates, can be polymers, surfactants, and biomolecules ${ }^{17-25}$ that assist in the control and changes of material properties. The literature reports that the use of substances such as caffeine, starch, vitamin C, albumin, gelatin ${ }^{18,23-25}$ as templates/additives affect the physico-chemical properties of the HAp particles. The use of sucrose has been widely reported for studies related to the formation of porous scaffolds ${ }^{26}$ However, there are studies that aim the synthesis of other materials, such as that carried out by Sabbaghan et al. ${ }^{27}$ who reported the use of sucrose for the synthesis of $\mathrm{ZnO}$ nanoparticles, motivating its use as a template in the synthesis of HAp.

Therefore, this work aimed the synthesis of hydroxyapatite by precipitation method using hen's eggshells as calcium source and sucrose as a template to evaluate its effects on the properties of the HAp obtained. A comparative study was also carried out with HAp sample obtained without sucrose to evaluate its effect on the characteristics of the synthesized materials.

\section{Experimental}

\subsection{Hen's eggshell treatment}

The hen's eggshell used in this work came from domestic consumption and only white shells have been selected as precursor material. The eggshells were initially washed in 
tap water and neutral soap to remove the excess of dirt and they were subsequently immersed in distilled water and heated for 30 minutes at $60{ }^{\circ} \mathrm{C}$. The material was dried at room temperature and then calcined in a muffle at $1000{ }^{\circ} \mathrm{C}$ for two hours to eliminate all organic material and convert calcium carbonate $\left(\mathrm{CaCO}_{3}\right)$ into calcium oxide $(\mathrm{CaO})$.

\subsection{Hydroxyapatite nanostructure synthesis}

A $50 \mathrm{~mL}$ solution of $\mathrm{Ca}(\mathrm{OH})_{2}$, was prepared from $2.7 \mathrm{~g}$ of the $\mathrm{CaO}$ obtained. A $50 \mathrm{~mL}$ of sucrose (ProQuímico) solution $(0.5,1,2,3$ and $4 \mathrm{~g})$ was prepared and added to $\mathrm{Ca}(\mathrm{OH})_{2}$ solution previously prepared. The mixture was stirred for 30 minutes at room temperature. After, $50 \mathrm{~mL}$ of the $\mathrm{H}_{3} \mathrm{PO}_{4}(85 \%$, ISOFAR) solution was added at a rate of $3.33 \mathrm{~mL} \cdot \mathrm{min}^{-1}{ }^{28}$ by a peristaltic pump (Milan-model 626). The whole solution was stirred using a mechanical stirrer (Quimis-Q-235-1). The reaction was carried out at room temperature and the $\mathrm{pH}$ was maintained at $12^{29} \mathrm{using}$ $\mathrm{NH}_{4} \mathrm{OH}$ (ISOFAR) when necessary. At the end of the acid addition, the precipitate obtained was aged for 1 hour at room temperature under constant agitation. The material obtained was vacuum filtered, washed several times with distilled water to remove the excess of $\mathrm{NH}_{4} \mathrm{OH}$, dried at $100{ }^{\circ} \mathrm{C}$ for $5 \mathrm{~h}$ (HAS0.5, HAS1, HAS2, HAS3, and HAS4) and then calcined at $600{ }^{\circ} \mathrm{C}$ for $2 \mathrm{~h}$ (HAS0.5-600, HAS1600, HAS2-600, HAS3-600 and HAS4-600). The samples were coded according to the amount of sucrose used, and the calcination temperature was added to differentiate them after heat treatment. For comparative purposes, a sample of HAp without sucrose was synthesized according to the same conditions described (HAp-600).

\subsection{Samples characterization}

\subsubsection{X-Ray Fluorescence Spectroscopy (XRF)}

The $\mathrm{CaO}$ obtained from calcined hen's eggshell was analyzed using XRF technique. The sample was prepared with lithium tetraborate $\left(\mathrm{Li}_{2} \mathrm{~B}_{4} \mathrm{O}_{7}\right)$. The analysis was performed on a Fluorescence spectrometer model AXIOS-MAX from Panalytical.

\subsubsection{X-Ray Diffraction (XRD)}

The diffractograms were obtained in a Panalytical diffractometer, model X'Pert PRO MPD, copper radiation $\mathrm{CuK} \alpha, \lambda=0.15418 \mathrm{~nm}$, voltage of $40 \mathrm{kV}$ and current of 40 $\mathrm{mA}$. The scan was $2 \theta=10^{\circ}-80^{\circ}$, with $0.05^{\circ}$ per step and an acquisition rate of $2.5^{\circ} \mathrm{min}^{-1}$. The diffractograms were analyzed by Rietveld method using the TOPAS-academic software v. 5.0.

\subsubsection{Textural characterization}

The materials were characterized by $\mathrm{N}_{2}$ adsorption/ desorption analysis at $-196{ }^{\circ} \mathrm{C}$ using Micromeritics ASAP 2010 equipment by the BET (Brunauer, Emmett and Teller) and BJH (Barrett, Joyner and Halenda) method.

\subsubsection{Fourier Transform Infrared Spectroscopy (FTIR)}

The analysis was performed at $400-4000 \mathrm{~cm}^{-1}$ regions using a Perkin Elmer Spectrum Two spectrometer with a resolution of $4 \mathrm{~cm}^{-1}$. The samples were previously dried, mixed in $\mathrm{KBr}$ and pressed to obtain pellets.

\subsubsection{Thermogravimetric analysis (TGA)}

The study of thermal behavior was performed using simultaneous thermal analysis equipment STA 449 F3 Jupiter, with air flow $\left(10 \mathrm{~mL} \cdot \mathrm{min}^{-1}\right)$ and heating rate of $15^{\circ} \mathrm{C} \cdot \mathrm{min}^{-1}$, from room temperature $\left(25^{\circ} \mathrm{C}\right)$ up to $600^{\circ} \mathrm{C}$ for $4 \mathrm{~h}$. Alumina $\left(\alpha-\mathrm{Al}_{2} \mathrm{O}_{3}\right)$ was used as reference material.

\subsubsection{Scanning Electron Microscopy (SEM)}

The SEM analysis was performed using the JSM-7100F (JEOL) model microscope, operating on high vacuum modes, with electron beam voltage between 1 and $15 \mathrm{kV}$.

\subsubsection{Transmission Electron Microscopy (TEM)}

Transmission Electron Microscopy (TEM) images have been obtained using a FEI-Titan 80-300 microscopes with Cs corrector working at 80 and $300 \mathrm{kV}$ operating in bright field (BF), dark field (DF), diffraction pattern (DP) and scan mode (STEM) using a high-angle annular dark-field detector (STEM-HAADF) and X-ray scattered energy spectroscopy (EDXS). And JEOL JEM-2100F operating at $200 \mathrm{kV}$ in bright field (BF). The particles were deposited in copper $(\mathrm{Cu})$ grids, with carbon film "holey" from a suspension previously prepared in isopropyl alcohol.

\subsection{In vitro assay: Indirect cytotoxicity}

The cytotoxicity test was performed for samples HAS3600 and HAp-600 on dental pulp stem cells by resazurin reduction assay according to ISO $10993-5^{30}$. The cells were cultured in DMEM (Sigma-Aldrich), with $4500 \mathrm{mg} . \mathrm{L}^{-1}$ glucose, in the presence of $10 \%$ FBS (Gibco), and 1\% Penicillin/ Streptomycin (Sigma-Aldrich) at $37{ }^{\circ} \mathrm{C}$ under a humidified at an atmosphere of $5 \% \mathrm{CO}_{2}$ incubator.

For the indirect assay, the samples extracts were obtained by incubating $0.1 \mathrm{~g}$ of dry material per $\mathrm{mL}$ of culture medium for $24 \mathrm{~h}$ (extract 1) and $48 \mathrm{~h}$ (extract 2) in the incubator at $37^{\circ} \mathrm{C}, 5 \% \mathrm{CO}_{2}$ atmosphere. The cells were seeded in a 96-well plate at a density of $4 \times 10^{4}$ cells. well ${ }^{-1}$ and cultured for $24 \mathrm{~h}$ to allow cell adhesion. After $24 \mathrm{~h}$, the cells were incubated with $100 \mu \mathrm{L}$ of the extracts for more $24 \mathrm{~h}\left(37^{\circ} \mathrm{C}, 5 \% \mathrm{CO}_{2}\right.$, humidified atmosphere). For positive viability reference (positive control) was used supplemented culture medium, while $50 \%$ (v/v) of dimethyl sulfoxide (DMSO) with supplemented culture medium was used as negative reference (negative control). All experiments were performed in triplicate. After the incubation period, the extracts were replaced for $200 \mu \mathrm{L}$ of resazurin solution (Sigma-Aldrich) $\left(0.5 \mathrm{mg} . \mathrm{L}^{-1}\right.$ resazurin in PBS, diluted in standard culture medium at $50 \% \mathrm{v} / \mathrm{v})^{31}$. The cells were again incubated for $4 \mathrm{~h}$. After incubation, $100 \mu \mathrm{L}$ aliquots were collected and transferred to another 96-well plate, where fluorescence analysis was performed on a spectrophotometer with a microplate reader (Biotek Synergy HT) at wavelengths of $530 \mathrm{~nm}$ excitation and $590 \mathrm{~nm}$ emission. The percentage of viable cells was calculated from the average values of absorbance for each sample concerning the positive control defined as $100 \%$. 


\section{Results and Discussion}

\subsection{Characterization of calcium oxide ( $\mathrm{CaO})$}

Figure 1 shows the XRD diffractogram and the XRF results of the $\mathrm{CaO}$ obtained from hen's eggshells calcined. The diffractogram shows the peaks exclusively for $\mathrm{CaO}$, indexed according to ICSD 52783, indicating that the temperature and time used were sufficient for the complete transformation of $\mathrm{CaCO}_{3}$ into $\mathrm{CaO}$, as also reported by Caliman et al. ${ }^{32}$ for ostrich eggshells.

In the $\mathrm{XRF}$ analysis, the compounds $\mathrm{P}_{2} \mathrm{O}_{6}$ and $\mathrm{SrO}$ were identified in low amounts of 0.42 and $0.31 \%$, respectively. Calcium oxide $(\mathrm{CaO})$ is the major constituent, with $99.27 \%$. The presence of $\mathrm{Sr}$ ions is extremely important, as these ions contribute to the formation of bone, acting on its resistance, which can be beneficial in osteoporosis treatments ${ }^{33}$. The presence of this element does not change the structural characteristics of HAp or another calcium phosphate compound and can improve biological performance in biocompatible applications, such as implants ${ }^{34}$. Besides that, these characteristics make the synthesized HAp closer to the bone's natural HAp.

\subsection{Characterization of synthesized samples}

\subsubsection{Thermogravimetric analysis (TGA)}

Figure 2 shows the TGA of the HAS3 sample. The sample presented approximately $13 \%$ of mass loss. TGA analysis was performed to verify the complete degradation of sucrose at a temperature of $600{ }^{\circ} \mathrm{C}$. According to DAS $(2001)^{35}$ the temperature required to complete removal of sucrose is at least $600^{\circ} \mathrm{C}$. Mass loss up to $150{ }^{\circ} \mathrm{C}$ refers to the evaporation of water adsorbed on the material surface, from $150^{\circ} \mathrm{C}$ to $250^{\circ} \mathrm{C}$ corresponding to sucrose dehydration and in the range 250 to $550^{\circ} \mathrm{C}$ corresponding to the sucrose degradation ${ }^{35}$. After $120 \mathrm{~min}$ of heating at $600^{\circ} \mathrm{C}$ the material was quite stable, justifying the time used in the heat treatment.

\subsubsection{X-Ray Diffraction (XRD)}

Figure 3 shows the XRD patterns of the synthesized HAp prepared with different concentrations and the absence of sucrose. As shown in the Figure 3, all the samples have similar XRD patterns, being exclusively composed by hydroxyapatite according to the ICSD 34457.

The temperature of $600{ }^{\circ} \mathrm{C}$ used in the heat treatment did not favor the formation of secondary phases. The diffractograms has a profile similar to that of "green samples" where the three main planes, located at (211), (112) and (300), are in overlapping indicating that the atoms are not perfectly ordered. When compared with the HAp-600 sample, it is possible to realize that some peaks become a little wider with a higher concentration of sucrose as can be seen in the peaks at $2 \theta$ equal to $32.196^{\circ}$ and $32.902^{\circ}$ in relation to the planes (112) and (300), respectively. This behavior in the HAp profile presented in those crystal planes was reported by Shu et al. ${ }^{25}$ when used different concentrations of gelatin in the synthesis of HAp which may justify a retard in the growth of crystals providing smaller crystallite sizes. In reaction with phosphoric acid, a careful procedure has been taken to maintain the $\mathrm{pH}$ at 12 , since in this range, the formation of

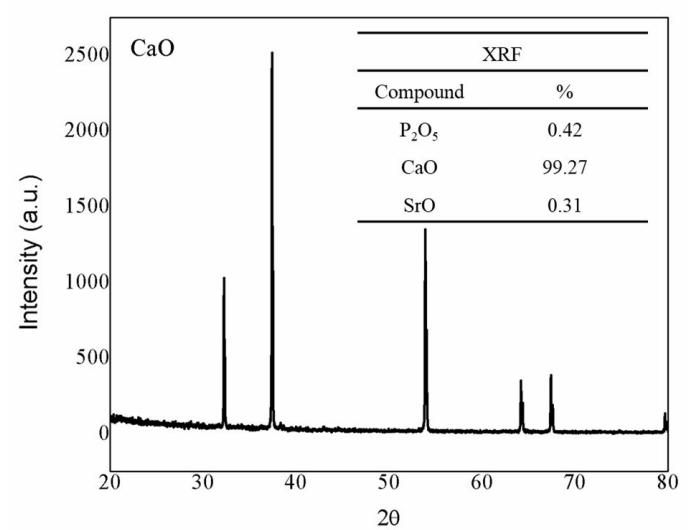

Figure 1. XRD pattern and XRF results for $\mathrm{CaO}$ obtained after calcination of eggshells.

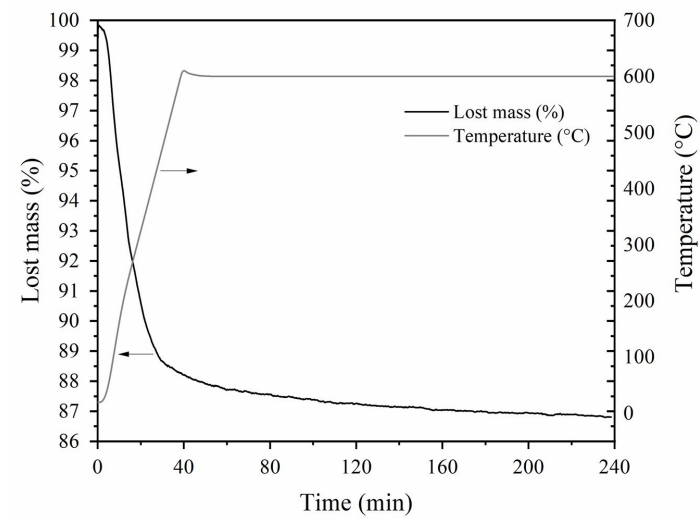

Figure 2. Thermogravimetric analysis of the HAS3 sample.

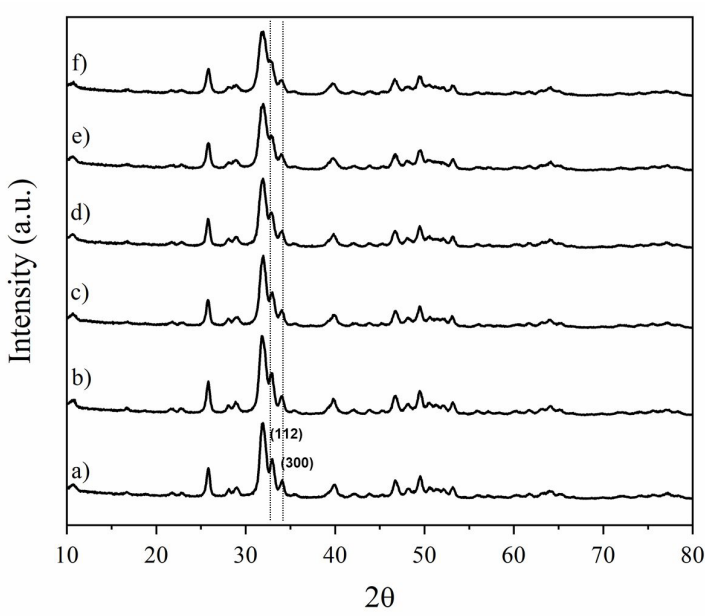

Figure 3. XRD patterns of (a) HAp-600, (b) HAS0.5-600, (c) HAS1600, (d) HAS2-600, (e) HAS3-600 and (f) HAS4-600 samples.

the $\mathrm{PO}_{4}^{-3}$ ion for the formation of HAp is assured ${ }^{29}$. Table 1 shows the crystallite sizes and GOF (goodness of fitting) values of the samples obtained by the Rietveld method. GOF is a statistical parameter used to assess the quality of the refinement. Values lower than 5, for high signal-noise ratio data, indicate an adequate refinement. 
Table 1. Crystallite size and GOF values of the synthesized samples.

\begin{tabular}{ccc}
\hline Samples & Crystallite size (nm) & GOF \\
\hline HAp-600 & 21.81 & 1.58 \\
\hline HAS0.5-600 & 22.38 & 1.50 \\
\hline HAS1-600 & 19.70 & 1.54 \\
\hline HAS2-600 & 20.25 & 1.50 \\
\hline HAS3-600 & 15.33 & 1.64 \\
\hline HAS4-600 & 16.33 & 1.47 \\
\hline
\end{tabular}

The refinement by Rietveld method presented GOF values between 1.50 and 1.64, which indicates an excellent quality of experimental data refinement. The samples have crystallite size of $21.81,22.38,19.70,20.25,15.33$, and $16.33 \mathrm{~nm}$ referring to HAp-600, HA0.5-600, HA1-600, HA2-600, HA3-600, and HA4-600, respectively. The HAS3.600 and HAS4-600 samples with the highest amounts of sucrose had smaller crystallite sizes as also reported by Brundavanam et al. ${ }^{36}$ when using gelatin. As well as the specific surface area, crystallite size affect the material's bioactivity response, previous results already reported that less crystalline materials increase the functions of osteoblasts and are more bioresorbable ${ }^{37-39}$.

\subsubsection{Textural characterization}

The literature mentions different substances used as a template ${ }^{18-25,40}$ which aims to improve some properties of the material, changing its morphology, increasing the specific surface area and pore size, and also decreasing the particle size. Some additives/templates used, such as surfactants, may have elements that can be difficult to remove, contaminating the biomaterial. Therefore, the use of sucrose is promising because is inexpensive and free of toxic elements ${ }^{41}$. Table 2 shows the values obtained for a specific surface area, pore size and pore volume obtained through the analysis of adsorption and desorption of $\mathrm{N}_{2}$ by BET and BJH methods.

The HAp-600 sample had a specific surface, pore volume and pore diameter of $36.74 \mathrm{~m}^{2} \cdot \mathrm{g}^{-1}, 0.206 \mathrm{~cm}^{3} \cdot \mathrm{g}^{-1}$ and 224.03 $\AA$, respectively. The samples HAS0.5-600, HAS1-600, HAS2600, HAS3-600, and HAS4-600 presented values for the specific surface of $63,82,77,93$, and $69 \mathrm{~m}^{2} \cdot \mathrm{g}^{-1}$, respectively. It is possible to observe that sucrose provided changes in the specific surface area when compared to the HAp-600 sample which has $36 \mathrm{~m}^{2} \cdot \mathrm{g}^{-1}$. However, the HAS4-600 sample showed a significant decrease in this value. Similar behavior was reported by Zhou et al. ${ }^{23}$ and $\mathrm{Wu}$ et al. ${ }^{42}$, where the authors used vitamin $\mathrm{C}$ and $\mathrm{CTAB}$ as a template, respectively, to obtain mesoporous HAp. Zhou et al. ${ }^{23}$ used 0.01 and $0.1 \mathrm{~g}$ of vitamin $\mathrm{C}$ and the highest amount did not provide the largest specific surface area. Wu et al. ${ }^{42}$ used different concentrations of CTAB and observed an increase in the specific surface area as the CTAB concentration increased, however a decrease was also observed in relation to the larger quantities used, as also observed in this work. Prae-Ravee et al. ${ }^{24}$ obtained HAp derived from eggshell using albumin as a template, having a specific surface values in the range of 17 to $21 \mathrm{~m}^{2} \cdot \mathrm{g}^{-1}$ and pore size of 80 to $150 \AA$. The use of sucrose in relation to albumin showed better results related to the increase of the specific surface area. Therefore, the results obtained in this work are superior to those reported by Prae-Ravee et al. ${ }^{24}$ and show that the use of sucrose as a template is very promising.

The degradation of sucrose, during calcination, can provide the formation of pores, which contributes for increasing the specific surface. There is a very large release of gases which leads to the formation of channels in the material providing the formation of pores ${ }^{43}$.

The values of pore size (Table 2 ) for samples synthesized with sucrose were in the range of $230-360 \AA$, which is classified as mesoporous material according to IUPAC. The HAS0.5-600 and HAS2-600 samples presented the highest values of pore size. The sucrose also caused considerable change in the volume of pores, varying from 0.49 to $0.64 \mathrm{~cm}^{3} \cdot \mathrm{g}^{-1}$, higher than HAp-600 control sample, with $0.2058 \mathrm{~cm}^{3} \cdot \mathrm{g}^{-1}$.

Figure 4 shows the $\mathrm{N}_{2}$ adsorption/desorption isotherm and the pore size distribution obtained by the BJH method of the HAS3-600 sample. All synthesized samples had type IV isotherms with hysteresis formation ${ }^{17,44}$. The different amounts of sucrose during the synthesis did not change the profile of the obtained isotherms. The materials had a narrow pore size of $200-400 \AA$ with pore size distribution curves centered at 325, 240, 330, 255 and $295 \AA$ for samples HAS0.5-600, HAS1-600, HAS2-600, HAS3-600, and HAS4-600, respectively, suggesting that these sizes are predominant in the samples.

Porosity and pore size have direct implications for the materials functionality during biomedical applications. The pores are important because they increase and facilitate the circulation of body fluids in addition to providing a greater area of interaction for substances such as proteins. The pore diameter values qualify the materials obtained to be used in drug delivery systems, for example. The pore diameter has a strong influence on the release rate of the molecules. The specific surface area, size and volume of the pore are factors that can influence the adsorption and release kinetics of drugs ${ }^{45,46}$.

It is important to note that all the materials synthesized in this work have high BET area when compared to most of the results reported in the literature for mesoporous calcium phosphates that used some additive $\mathrm{e}^{17,34,47}$. These results support the use of sucrose as an excellent additive to act on changes in material properties.

\subsubsection{Fourier Transform Infrared Spectroscopy (FTIR)}

Figure 5 shows the FTIR spectra of the obtained samples. The FTIR spectra of all samples showed well-defined vibrational bands referring to the characteristic groups of the HAp phase, confirming the thermal stability of the materials to $600{ }^{\circ} \mathrm{C}$ and corroborating the results already shown of XRD. The spectrum has bands with high intensity in 1096$1044 \mathrm{~cm}^{-1}$ related to the $\mathrm{PO}_{4}^{-3}$ group. Less intense signals also referring to $\mathrm{PO}_{4}^{-3}$ were identified at shorter wavelengths, such as $963,603,566$ and $474 \mathrm{~cm}^{-1}$.

The wide band at $3300-3600 \mathrm{~cm}^{-1}$ range is characteristic of materials containing hydroxyl radicals ${ }^{48}$. The wide band at $3437 \mathrm{~cm}^{-1}$ corresponding to the vibration of the adsorbed $\mathrm{H}_{2} \mathrm{O}$ to the structure of the HAp and the peak at $3572 \mathrm{~cm}^{-1}$ is attributed to $\mathrm{OH}^{-}$of HAp. HAp is the only calcium phosphate that presents this vibrational mode in $3572 \mathrm{~cm}^{-1} 49 . \mathrm{OH}^{-}$bands were also detected at $628 \mathrm{~cm}^{-1}$ and less intense $\mathrm{H}_{2} \mathrm{O}$ bands 
Table 2. Textural parameters of the synthesized samples.

\begin{tabular}{cccc}
\hline Samples & $\begin{array}{c}\text { BET area } \\
\left(\mathbf{m}^{\mathbf{2}} \cdot \mathbf{g}^{-\mathbf{1}}\right)\end{array}$ & Pore size $(\AA)$ & $\begin{array}{c}\text { Pore volume } \\
\left(\mathbf{c m}^{\mathbf{3}} \cdot \mathbf{g}^{-1}\right)\end{array}$ \\
\hline HAp-600 & 36.74 & 224.03 & 0.2058 \\
\hline HAS0.5-600 & 63.00 & 353.13 & 0.5568 \\
\hline HAS1-600 & 82.00 & 237.57 & 0.4921 \\
\hline HAS2-600 & 77.00 & 329.04 & 0.6382 \\
\hline HAS3-600 & 93.00 & 258.64 & 0.6049 \\
\hline HAS4-600 & 69.00 & 295.49 & 0.5108 \\
\hline
\end{tabular}

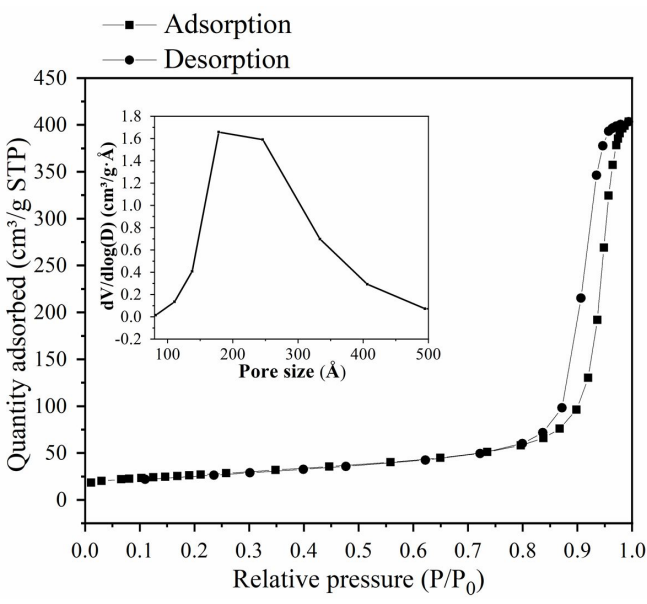

Figure 4. Adsorption/desorption isotherm of $\mathrm{N}_{2}$ of the HAS3.600 sample. The pore size distribution by the BJH method is shown inserted in the figure.

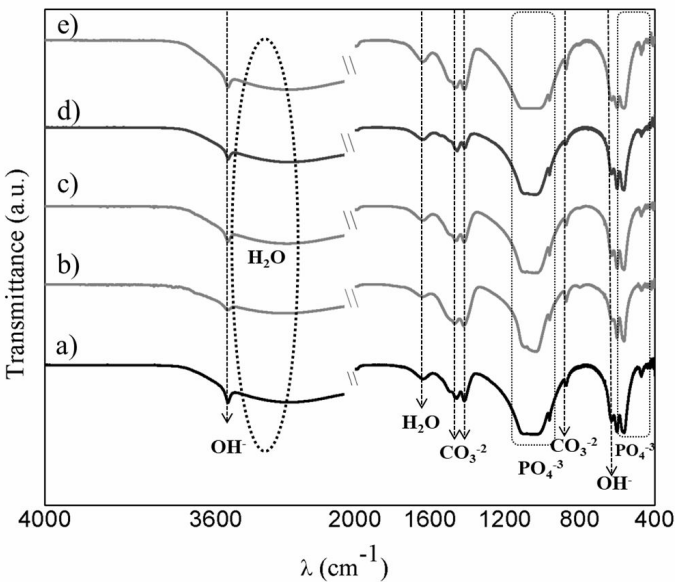

Figure 5. FTIR spectra of the (a) HAS0.5-600, (a) HAS1-600, (c) HAS2-600, (d) HAS3-600 and (e) HAS4-600 samples.

were also observed at $1640 \mathrm{~cm}^{-1}$. The results obtained are in accordance with those reported in the literature for the position of the vibrational bands of each HAp group ${ }^{25,36,50,51}$.

Absorption bands were identified at 875 and $1460 \mathrm{~cm}^{-1}$ that are attributed to the vibrational modes of substitution of $\mathrm{PO}_{4}^{-3}$ by carbonate, being described as type-B substitution ${ }^{10,52-54}$. The presence of carbonate groups in the HAp structure is characteristic of materials obtained in an uncontrolled atmosphere.

The anionic locations in the HAp structure are very susceptible to $\mathrm{CO}_{2}$ from the atmosphere, occurring these substitutions in the HAp network ${ }^{54}$. The presence of carbonate groups is common in biological HAp, this ion is the highest concentration, from 4 to $6 \%$ of ions ${ }^{55}$, making the synthesized materials analogous to biological apatites. Its replacement in the network does not disqualify its use as biomaterial since the composition of human bones and teeth contains carbonate as substitute ions ${ }^{56,57}$. No sucrose characteristic bands were identified.

\subsubsection{Scanning Electron Microscopy (SEM)}

The samples micrographs with different amounts of sucrose and the HAp-600 control sample are shown in Figure 6. The HAp-600 sample has a rod-like morphology, and in the HAp samples synthesized in the presence of sucrose, it is possible to observe a variation of the morphology as the sucrose concentration increases. In addition to the change in morphology, there was a narrowing of the particles, as can be seen in the HAS1-600 sample. This comparison is possible because the micrographs are at the same magnification of 100kx. Samples HAS0.5-600, HAS1-600, and HAS2-600 present a mixture of morphology, with rod-like and rounded edge or an irregular morphology. The samples HAS3-600 and HAS4-600 have a predominance of rounded structure ${ }^{58}$ and all the samples are composed of many clusters. Nanoparticles have a great tendency to cluster because they have a low volume, their area-volume ratio is much greater when compared to particles on a micro or submicron scale. The high surfaces of the particles have Van der Waals interactions that result in a strong tendency to agglomerate ${ }^{59,60}$.

\subsubsection{Transmission Electron Microscopy (TEM)}

TEM analysis was performed to observe their morphologies in detail and to evaluate the particle size. Figures 7 and 8 present the results of the MET analysis of the samples HAp-600, synthesized in the absence of sucrose, and the HAS1-600 and HAS3-600 samples, synthesized with $1 \mathrm{~g}$ and $3 \mathrm{~g}$ of sucrose, respectively.

The HAp-600 sample has a rod-like morphology with length in the range of 50-60 nm and width in the range of $15-23 \mathrm{~nm}$ (Figure 7a), with regular particle size distribution. A complementary analysis was performed in the HAADFSTEM mode is shown in Figure 7b. Diffraction pattern, inserted in Figure 7a, shows the polycrystalline nature of the material ${ }^{61}$, composed of a series of diffraction spots of hydroxyapatite. It is possible to infer that the measured spots 0.341 and $0.272 \mathrm{~nm}$ correspond to HAp plans (002) and (300), respectively, indexed according to ICSD 34457. A chemical analysis of energy dispersion X-ray spectroscopy (EDXS) was carried out and the results are shown in the graph inserted in Figure 7b. The chemical elements O, P, and $\mathrm{Ca}$ were identified and corresponding to the composition of HAp. The carbon present in the EDXS comes from the material of the sample support grid used in the analysis. In Figure $7 \mathrm{c}$, marked with the black square, a high-resolution image (HRTEM) was made as shown in Figure 7d. In this region (Figure 7d), in a select area market with white square, 


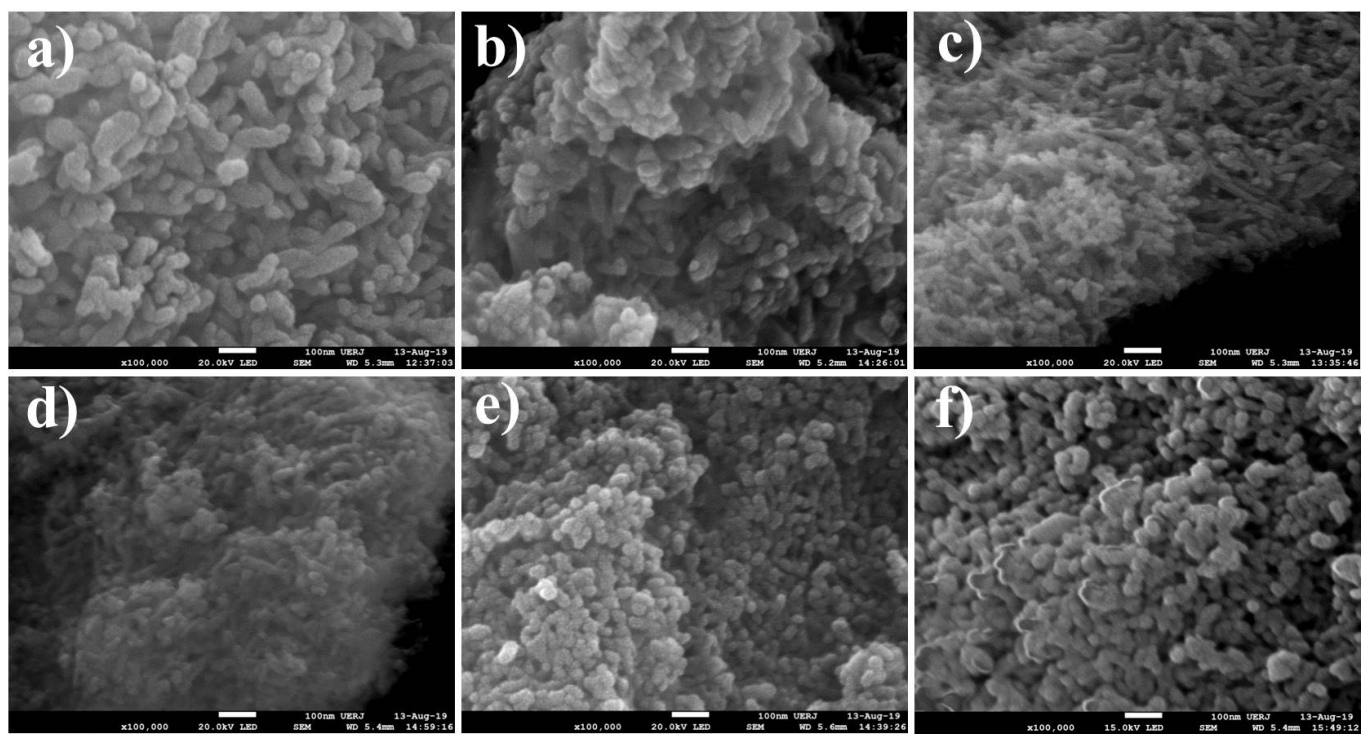

Figure 6. SEM micrographs of the (a) HAp-600, (b) HAS0.5-600, (c) HAS1-600, (d) HAS2-600, (e) HAS3-600 and (f) HAS4-600 samples.

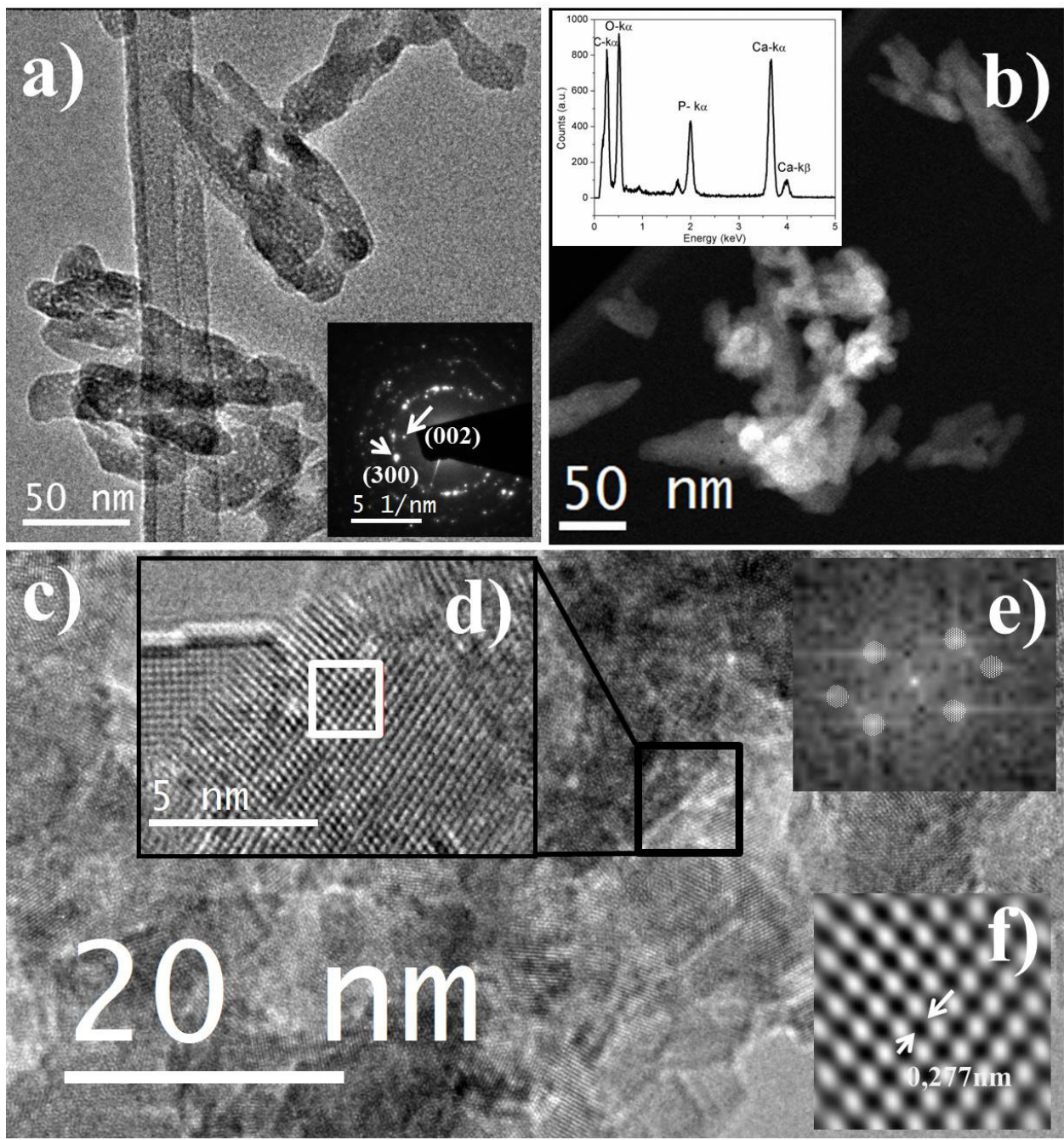

Figure 7. MET bright field image and diffraction pattern (a), HAADF - STEM image and EDXS (b), MET bright field image (c), HRTEM (d), FTT (e) and IFFT (f) of the HAp-600 sample. 


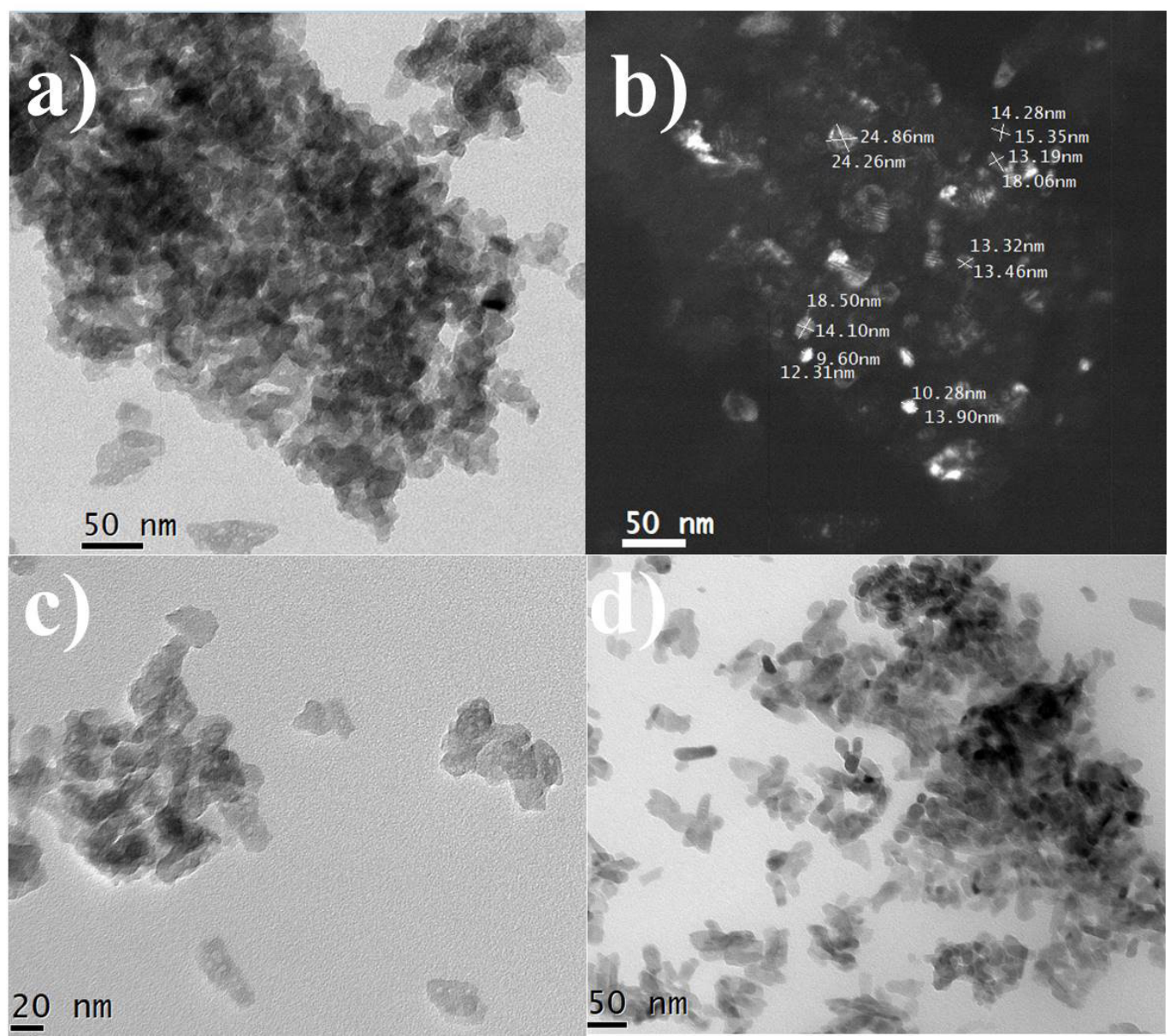

Figure 8. Bright field (a) and dark field (b) pair of the HAS1-600 sample and MET bright field image of samples (c) HAS1-600 and (d) HAS3-600.

the Fourier transform (FTT) was applied using the digital program Micrograph (Gatan, Inc.). To improve the noise, a mask was applied (Figure 7e) and then the corresponding inverse Fourier transform (Figure 7f). The measured interplanar distance, shown in the Figure 7f, was $0.277 \mathrm{~nm}$ indexed corresponding to the HAp plane (112) according to ICSD 34457.

Figure $8 \mathrm{a}$ and $8 \mathrm{~b}$ shows the bright and dark field pair of the HAS1-600 sample. The acquisition of these data helped to identify the sample's morphology and particle size. Nanoparticle aggregates with a diameter of around 10-30 nm and irregular shape are observed in HAS1-600 sample (Figure $8 \mathrm{a}, 8 \mathrm{~b}$ and $8 \mathrm{c}$ ). It is possible to observe that the material has facets. In the HAS3-600 sample (Figure 8d) it is possible to observe more defined particles, with more rounded edge and with a predominance of particles with width ranging from 9-15 $\mathrm{nm}$ and a length ranging from 20$30 \mathrm{~nm}$. These results, in comparison to Figure $7 \mathrm{a}$, confirm the sucrose influence on the final morphology and the growth of HAp nanoparticles. Thus, these results corroborate the SEM analysis about morphology and decrease of the particle size. The results indicate that the use of sucrose is promising for modifying particle size.
Sucrose is composed of many hydroxyl groups, providing a greater amount of reaction sites due to the interaction of $\mathrm{OH}^{-}$with $\mathrm{Ca}^{+2}$ by Van der Walls interaction, favoring the formation of many nucleation centers and its molecular structure is formed by a large chain. These last characteristic acts in decreasing the mobility of $\mathrm{Ca}^{+2}$ and $\mathrm{PO}_{4}^{-3}$ ions within the nucleus, affecting growth, providing smaller particles ${ }^{59}$.

The particle size is an important parameter in biomaterials synthesis since they reflect in the densification of the powder, sinterability as well as in its solubility in implants ${ }^{60}$.

\subsubsection{Indirect cytotoxicity}

Figure 9 shows the results obtained by resazurin reduction assay to cells for the $24 \mathrm{~h}$ incubation periods. The cell viability for extracts obtained in $24 \mathrm{~h}$ (extract 1 ) were $98.9 \pm 2.3 \%$ and $92.7 \pm 1.1 \%$ and for extracts obtained in $48 \mathrm{~h}$ (extract 2 ), were $90.3 \pm 0.3 \%$ and $87.7 \pm 0.5 \%$ for samples HAp- 600 and HAS3-600, respectively. The extracts of the samples HAp600 and HAS3-600 were tested to dental pulp stem cells to evaluate the metabolic function and cellular health. An ideal biomaterial should not release any toxic products or produce adverse reactions. The toxicity is related to degradation of biomaterials which stimulates or inhibits cellular metabolism ${ }^{62}$ 


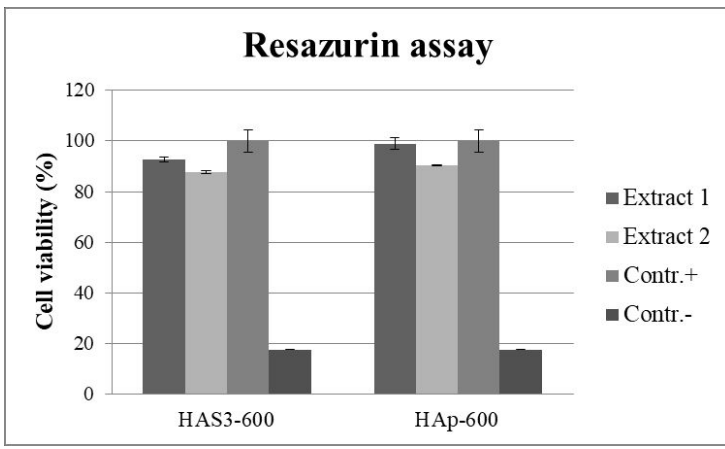

Figure 9. Cell viability for dental pulp cells in contact with the extracts obtained for $24 \mathrm{~h}$ (extract 1 ) and $48 \mathrm{~h}$ (extract 2 ) for a $24 \mathrm{~h}$ incubation period. Cell culture with supplemented culture medium was used as positive control (contr.+) and as negative control was used standard supplemented culture medium with $50 \%$ (v/v) DMSO.

making preliminary in vitro studies necessary. Resazurin reduction is a fast colorimetric method and has been used to measure cell proliferation and cytotoxicity ${ }^{31}$.

The analysis of Figure 9 allows to conclude that the samples did not present characteristics of cytotoxicity to the cells, since they presented values of cell viability above $85 \%$, for both extracts obtained in $24 \mathrm{~h}$ and $48 \mathrm{~h}$. There must be a decrease in cell viability by more than $30 \%$ to be considered cytotoxic, according to ISO $10993-5^{30}$. The difference observed between the results of extracts 1 and 2 is attributed to the ions release, which for $48 \mathrm{~h}$ was greater, increasing the interaction with the cells, presenting an impact on the cell viability, but not disqualifying the material since the results obtained are within required by ISO $10993-5^{30}$, over $70 \%$.

\section{Conclusion}

Hydroxyapatite samples using sucrose as a template were successfully synthesized by precipitation method using hen's eggshell as calcium source. Sucrose provided changes in the morphology of the materials, also acting in the reduction of particle size, increase of the specific surface and porosity. The in vitro assay by resazurin reduction demonstrated that the HAp samples are not cytotoxic, which makes the synthesized materials promising for biomedical applications. The use of eggshells is an excellent raw material for reducing process costs. And the use of sucrose as a template showed satisfactory acting on the properties of the synthesized materials.

\section{Acknowledgements}

The authors would like to acknowledge Carlos Chagas Filho Research Support Foundation of the State of Rio de Janeiro (FAPERJ), National Council for Scientific and Technological Development (CNPq) and Coordination for the Improvement of Higher Education Personnel (CAPES) for the grants, and the institutions PUC, UFRJ, Estácio de Sá University, NANOFAB/UERJ, LABC/UNICAMP, INMETRO and CBPF for their cooperation and support for the paper. The authors declare no conflicts of interest related to this study.

\section{References}

1. Dorozhkin SV. Nanosized and nanocrystalline calcium orthophosphates. Acta Biomater. 2010;6(3):715-34.

2. Zhou H, Lee J. Nanoscale hydroxyapatite particles for bone tissue engineering. Acta Biomater. 2011;7(7):2769-81.

3. Wang Y, Liu L, Guo S. Characterization of biodegradable and cytocompatible nano-hydroxyapatite/polycaprolactone porous scaffolds in degradation in vitro. Polym Degrad Stabil. 2010;95(2):207-13.

4. Dong Z, Li Y, Zou Q. Degradation and biocompatibility of porous nano-hydroxyapatite/polyurethane composite scaffold for bone tissue engineering. Appl Surf Sci. 2009;255(12):6087-91.

5. Cai Y, Liu Y, Yan W, Hu Q, Tao J, Zhang M, et al. Role of hydroxyapatite nanoparticle size in bone cell proliferation. J Mater Chem. 2007;17(36):3780-7.

6. Webster TJ, Ergun C, Doremus RH, Siegel RW, Bizios R. Enhanced osteoclast-like cell functions on nanophase ceramics. Biomaterials. 2001;22(11):1327-33.

7. Ramesh S, Loo ZZ, Tan CY, Chew WK, Ching YC, Tarlochan F, et al. Characterization of biogenic hydroxyapatite derived from animal bones for biomedical applications. Ceram Int. 2018;44(9):10525-30.

8. Shi P, Liu M, Fan F, Yu C, Lu W, Du M. Characterization of natural hydroxyapatite originated from fish bone and its biocompatibility with osteoblasts. Mater Sci Eng C. 2018;90:706-12.

9. Paul S, Pal A, Choudhury AR, Bodhak S, Balla VK, Sinha A, et al. Effect of trace elements on the sintering effect of fish scale derived hydroxyapatite and its bioactivity. Ceram Int. 2017;43(17):1567884.

10. Wu SC, Hsu HC, Hsu SK, Tseng CP, Ho WF. Preparation and characterization of hydroxyapatite synthesized from oyster shell powders. Adv Powder Technol. 2017;28(4):1154-8.

11. Jahan SA, Mollah MYA,Ahmed S, Susan MABH. Nano-hydroxyapatite prepared from eggshell-derived calcium-precursor using reverse microemulsions as nanoreactor. Materials Today: Proceedings. 2017;4(4):5497-506.

12. Rujitanapanich S, Kumpapan P, Wanjanoi P. Synthesis of hydroxyapatite from oyster shell via precipitation. Energy Procedia. 2014;56:112-7.

13. Horta M, Aguilar M, Moura F, Campos J, Ramos V, Quizunda A. Synthesis and characterization of green nanohydroxyapatite from hen eggshell by precipitation method. Materials Today: Proceedings. 2019;14:716-21.

14. Aguilar MS, Campos JB, Di Lello BC, Campos NC, Novaes L. Viabilidade do uso de cascas de ovos na síntese da hidroxiapatita utilizando o método sol-gel. Ponta Grossa: Editora Atena; 2019. p. 54-62. AAplicação do Conhecimento Científico nas Engenharias.

15. Gomes LC, Di Lello BC, Campos JB, Sampaio M. Síntese e caracterização de fosfatos de cálcio a partir da casca de ovo de galinha. Ceramica. 2012;(58):348

16. Sadat-Shojai M, Khorasani MT, Dinpanah-Khoshdargi E, Jamshidi A. Synthesis methods for nanosized hydroxyapatite with diverse structures. Acta Biomater. 2013;9(8):7591-621.

17. Wang H, Zhai L, Li Y, Shi T. Preparation of irregular mesoporous hydroxyapatite. Mater Res Bull. 2008;43(6):1607-14.

18. da Silva OG, Alves MM, dos Santos IMG, Fonseca MG, Jaber M. Mesoporous calcium phosphate using casein as a template: application to bovine serum albumin sorption. Colloids Surf B Biointerfaces. 2017;158:480-7.

19. Qi C, Musetti S, Fu LH, Zhu YJ, Huang L. Biomolecule-assisted green synthesis of nanostructured calcium phosphates and their biomedical applications. Chem Soc Rev. 2019;48(10):2698-737.

20. Saha SK, Banerjee A, Banerjee S, Bose S. Synthesis of nanocrystalline hydroxyapatite using surfactant template systems: role of templates in controlling morphology. Mater Sci Eng C. 2009;29(7):2294-301.

21. Yang S, Chen J, Wang Z, Zhang H, Zhang Q. Surfactant-assisted synthesis of oriented hydroxyapatite nanoclusters by refluxmethod. Mater Lett. 2013;96:177-80.

22. Zhu Y, Jiang Y, Zhu Z, Deng H, Ding H, Li Y, et al. Preparation of a porous hydroxyapatite-carbon composite with the bio-template 
of sugarcane top stems and its use for the $\mathrm{Pb}$ (II) removal. J Clean Prod. 2018;187:650-61.

23. Zhou H, Yang Y, Yang M, Wang W, Bi Y. Synthesis of mesoporous hydroxyapatite via a vitamin $\mathrm{C}$ templating hydrothermal route. Mater Lett. 2018;218:52-5.

24. Prae-Ravee K, Kuanchertchoo N, Wetprasit N, Supaphol P. Hydroxyapatite/ovalbumin composite particles as model protein carriers for bone tissue engineering: I. Synthesis and characterization. Mater Sci Eng C. 2012;32(4):758-62.

25. Shu C, Xianzhu Y, Zhangyin X, Guohua X, Hong L, Kangde Y. Synthesis and sintering of nanocrystalline hydroxyapatite powders by gelatin-based precipitation method. Ceram Int. 2007;33(2):193-6.

26. Rodrigues LR, Laranjeira MDS, Fernandes MH, Monteiro FJ, Zavaglia CADC. HA/TCP scaffolds obtained by sucrose crystal leaching method: preliminary in vitro evaluation. Mater Res. 2014;17(4):811-6.

27. Sabbaghan M, Firooz AA, Ahmadi VJ. The effect of template on morphology, optical and photocatalytic properties of $\mathrm{ZnO}$ nanostructures. J Mol Liq. 2012;175:135-40.

28. Ibrahim AR, Zhou Y, Li X, Chen L, Hong Y, Su Y, et al. Synthesis of rod-like hydroxyapatite with high surface area and pore volume from eggshells for effective adsorption of aqueous $\mathrm{Pb}$ (II). Mater Res Bull. 2015;62:132-41.

29. Lynn AK, Bonfield W. A novel method for the simultaneous, titrant-free control of $\mathrm{pH}$ and calcium phosphate mass yield. Acc Chem Res. 2005;38(3):202-7.

30. ISO: International Organization for Standardization. ISO 1099310995: Biological Evaluation of Medical Devices-Part 5: Tests for In Vitro Cytotoxicity. Geneva: ISO; 2009.

31. de Souza RFB, de Souza FCB, Rodrigues C, Drouin B, Popat KC, Mantovani D, et al. Mechanically-enhanced polysaccharide-based scaffolds for tissue engineering of soft tissues. Mater Sci Eng C. 2019;94:364-75.

32. Caliman LB, Silva SN, Junkes JA, Sagrillo VPD. Ostrich eggshell as an alternative source of calcium ions for biomaterials synthesis. Mater Res. 2017;20(2):413-7.

33. Dahl SG, Allain P, Marie PJ, Mauras Y, Boivin G, Ammann $\mathrm{P}$, et al. Incorporation and distribution of strontium in bone. Bone. 2001;28(4):446-53.

34. da Rocha DN, de Oliveira Cruz LR, de Campos JB, dos Santos JL, Marçal RLSB, Mijares DQ, et al. Bioactivity of strontium-monetite coatings for biomedical applications. Ceram Int. 2019;45(6):756879.

35. Das RN, Bandyopadhyay A, Bose $\mathrm{S}$. Nanocrystalline $\alpha-\mathrm{Al}_{2} \mathrm{O}_{3}$ using sucrose. J Am Ceram Soc. 2001;84(10):2421-3.

36. Brundavanam RK, Jian ZT, Chapman P, Le XT, Mondinos N, Fawcett D, et al. Effect of dilute gelatine on the ultrasonic thermally assisted synthesis of nano hydroxyapatite. Ultrason Sonochem. 2011;18(3):697-703.

37. LeGeros RZ. Calcium phosphates in oral biology and medicine. Monogr Oral Sci. 1991;15:1-201.

38. Prabakaran K, Rajeswari S. Spectroscopic investigations on the synthesis of nano-hydroxyapatite from calcined eggshell by hydrothermal method using cationic surfactant as template. Spectrochim Acta A Mol Biomol Spectrosc. 2009;74(5):1127-34.

39. Balasundaram G, Sato M, Webster TJ. Using hydroxyapatite nanoparticles and decreased crystallinity to promote osteoblast adhesion similar to functionalizing with RGD. Biomaterials. 2006;27(14):2798-805.

40. Varadarajan V, Varsha M, Vijayasekaran K, Shankar SV. Comparative studies of hydroxyapatite (HAp) nanoparticles synthesized by using different green templates. AIP Conference Proceedings. 2020;2040(1):080002.

41. Grant RL, Yao C, Gabaldon D, Acosta D. Evaluation of surfactant cytotoxicity potential by primary cultures of ocular tissues: I.
Characterization of rabbit corneal epithelial cells and initial injury and delayed toxicity studies. Toxicology. 1992;76(2):153-76.

42. Wu X, Song X, Li D, Liu J, Zhang P, Chen X. Preparation of mesoporous nano-hydroxyapatite using a surfactant template method for protein delivery. J Bionics Eng. 2012;9(2):224-33.

43. Bose S, Saha SK. Synthesis of hydroxyapatite nanopowders via sucrose-templated sol-gel method. JAm Ceram Soc. 2003;86(6):10557.

44. Ng S, Guo J, Ma J, Loo SCJ. Synthesis of high surface area mesostructured calcium phosphate particles. Acta Biomater. 2010;6(9):3772-81.

45. Rawlings RD. Bioactive glasses and glass-ceramics. Clin Mater. 1993;14(2):155-79.

46. Ohgushi H, Okumura M, Yoshikawa T, Inboue K, Senpuku N, Tamai S, et al. Bone formation processin porous calcium carbonate and hydroxyapatite. J Biomed Mater Res. 1992;26(7):885-95.

47. Zhao J, Zhu YJ, Zheng JQ, Chen F, Wu J. Microwave-assisted hydrothermal preparation using adenosine 5 '-triphosphate disodium salt as a phosphate source and characterization of zincdoped amorphous calcium phosphate mesoporous microspheres. Microporous Mesoporous Mater. 2013;180:79-85.

48. Ma X, Chen Y, Qian J, Yuan Y, Liu C. Controllable synthesis of spherical hydroxyapatite nanoparticles using inverse microemulsion method. Mater Chem Phys. 2016;183:220-9.

49. Chang MC, Douglas WH, Tanaka J. Organic-inorganic interaction and the growth mechanism of hydroxyapatite crystals in gelatin matrices between $37^{\circ}$ and $80^{\circ}$ C. J Mater Sci Mater Med. 2006;17(4):387-96.

50. Othmani M,Aissa A, Grelard A, Das RK, Oda R, Debbabi M. Synthesis and characterization of hydroxyapatite-based nanocomposites by the functionalization of hydroxyapatite nanoparticles with phosphonic acids. Colloids Surf A Physicochem Eng Asp. 2016;508:336-44.

51. Higuita LP, Vargas AF, Gil MJ, Giraldo LF. Synthesis and characterization of nanocomposite based on hydroxyapatite and monetite. Mater Lett. 2016;175:169-72.

52. Landi E, Celotti G, Logroscino G, Tampieri A. Carbonated hydroxyapatite as bone substitute. J Eur Ceram Soc. 2003;23(15):2931-7.

53. Ramesh S, Natasha AN, Tan CY, Bang LT, Niakan A, Purbolaksono $\mathrm{J}$, et al. Characteristics and properties of hydoxyapatite derived by sol-gel and wet chemical precipitation methods. Ceram Int. 2015;41(9):10434-41.

54. Koutsopoulos S. Synthesis and characterization of hydroxyapatite crystals: a review study on the analytical methods. J Biomed Mater Res. 2002;62(4):600-12.

55. Dorozhkin SV. Calcium orthophosphates in nature, biology and medicine. Materials (Basel). 2009;2(2):399-498.

56. Ramesh S, Natasha AN, Tan CY, Bang LT, Ching CY, Chandran H. Direct conversion of eggshell to hydroxyapatite ceramic by a sintering method. Ceram Int. 2016;42(6):7824-9.

57. Olszta MJ, Cheng X, Jee SS, Kumar R, Kim YY, Kaufman MJ, et al. Bone structure and formation: A new perspective. Mater Sci Eng Rep. 2007;58(3-5):77-116.

58. Akram M, Alshemary AZ, Goh YF, Ibrahim WAW, Lintang HO, Hussain R. Continuous microwave flow synthesis of mesoporous hydroxyapatite. Mater Sci Eng C. 2015;56:356-62.

59. Sanosh KP, Chu MC, Balakrishnan A, Lee YJ, Kim TN, Cho SJ. Synthesis of nano hydroxyapatite powder that simulate teeth particle morphology and composition. Curr Appl Phys. 2009;9(6):1459-62.

60. LeGeros RZ. Biodegradation and bioresorption of calcium phosphate ceramics. Clin Mater. 1993;14(1):65-88.

61. Sanosh KP, Chu MC, Balakrishnan A, Kim TN, Cho SJ. Utilization of biowaste eggshells to synthesize nanocrystalline hydroxyapatite powders. Mater Lett. 2009;63(24-25):2100-2.

62. Li W, Zhou J, Xu Y. Study of the in vitro cytotoxicity testing of medical devices. Biomed Rep. 2015;3(5):617-20. 